Prepared for the U.S. Department of Energy

under Contract DE-AC05-76RL01830

\title{
The Continued Need for Modeling and Scaled Testing to Advance the Hanford Tank Waste Mission
}

\author{
LM Peurrung \\ JA Fort \\ DR Rector
}

September 2013

\section{Pacific Northwest}

NATIONAL LABORATORY

Proudly Operated by Battelle Since 1965 


\title{
DISCLAIMER
}

This report was prepared as an account of work sponsored by an agency of the United States Government. Neither the United States Government nor any agency thereof, nor Battelle Memorial Institute, nor any of their employees, makes any warranty, express or implied, or assumes any legal liability or responsibility for the accuracy, completeness, or usefulness of any information, apparatus, product, or process disclosed, or represents that its use would not infringe privately owned rights. Reference herein to any specific commercial product, process, or service by trade name, trademark, manufacturer, or otherwise does not necessarily constitute or imply its endorsement, recommendation, or favoring by the United States Government or any agency thereof, or Battelle Memorial Institute. The views and opinions of authors expressed herein do not necessarily state or reflect those of the United States Government or any agency thereof.

\author{
PACIFIC NORTHWEST NATIONAL LABORATORY \\ operated by \\ BATTELLE \\ for the \\ UNITED STATES DEPARTMENT OF ENERGY \\ under Contract DE-AC05-76RL01830
}

Printed in the United States of America
Available to DOE and DOE contractors from the Office of Scientific and Technical Information,
P.O. Box 62, Oak Ridge, TN 37831-0062;
ph: (865) 576-8401
fax: $(865)$ 576-5728
email: reports@adonis.osti.gov

\begin{abstract}
Available to the public from the National Technical Information Service, U.S. Department of Commerce, 5285 Port Royal Rd., Springfield, VA 22161 ph: (800) 553-6847 fax: $(703) 605-6900$ email: orders@ntis.fedworld.gov online ordering: http://www.ntis.gov/ordering.htm
\end{abstract}

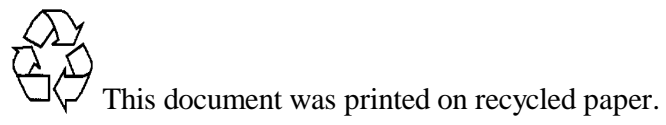




\section{The Continued Need for Modeling and Scaled Testing to Advance the Hanford Tank Waste Mission \\ WHY WE NEED TO RETRIEVE THE BABY FROM THE BATHWATER}

\section{Summary}

Hanford tank wastes are chemically complex slurries of liquids and solids that can exhibit changes in rheological behavior during retrieval and processing. The Hanford Waste Treatment and Immobilization Plant (WTP) recently abandoned its planned approach to use computational fluid dynamics (CFD) supported by testing at less than full scale to verify the design of vessels that process these wastes within the plant. The commercial CFD tool selected was deemed too difficult to validate to the degree necessary for use in the design of a nuclear facility. Alternative, but somewhat immature, CFD tools are available that can simulate multiphase flow of non-Newtonian fluids. Yet both CFD and scaled testing can play an important role in advancing the Hanford tank waste mission-in supporting the new verification approach, which is to conduct testing in actual plant vessels; in supporting waste feed delivery, where scaled testing is ongoing; as a fallback approach to design verification if the Full Scale Vessel Testing Program is deemed too costly and time-consuming; to troubleshoot problems during commissioning and operation of the plant; and to evaluate the effects of any proposed changes in operating conditions in the future to optimize plant performance.

It is recommended that a CFD modeling and scaled testing task be initiated which would support tank farms and full scale vessel testing (FSVT) for WTP. This would include the following specific actions:

1. Re-integrate best-in-class CFD tools for modeling non-Newtonian slurry behavior in Hanford tank waste unit operations, including WTP and tank farms. This should begin with an assessment of potential candidate CFD tools to evaluate their ability, readiness, and capabilities through demonstration calculations on test problems with multiphase flow behavior.

2. Use scaled testing, as needed, to give insight into multiphase fluid physical behavior typical of Hanford mixing and transport processes, help predict full-scale performance, and validate selected computational tools.

\section{Situation Analysis}

Progress toward completing the design and construction of WTP has been stymied in part by technical questions regarding the performance of mixing and transfer systems in the plant and associated nuclear safety issues. There is limited operational experience globally with the pulse-jet mixers (PJMs) being installed inside the plant's "black cells," particularly for the tall vessel geometries and the relatively high solids concentrations planned in several vessels. Industry mitigates the technical and financial risks for one-of-a-kind chemical processing plant construction such as W'TP through integrated scaled testing and modeling. While scaled testing has been effectively used at Hanford on many programs (such as flammable gas safety (Stewart 2006) and tank waste pretreatment (Kurath et al. 2009)), the development and shared use of models, specifically CFD models, has been limited. WTP had, in fact, supported a decade of scaled testing (Beeman 2010) and had invested \$40M in a commercially available CFD model (Fluent) that was adapted and customized to simulate pulse-jet mixing in plant vessels. However, WTP's plan to base design verification on Fluent was recently rejected (DOE 2012). CFD tools were deemed too difficult for use in verifying and validating the design of a nuclear facility. Scaled testing was also abandoned at the same time due to concerns that scaling relationships were not technically defensible or expedient. Design verification is instead being pursued with the support of data from full scale tests using the actual plant vessels, at high cost and schedule impact. Both CFD and scaled testing received a black eye in the process.

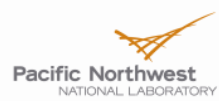


And yet, there are still several areas within the Hanford tank waste mission that would clearly benefit from CFD and/or scaled testing - including the FSVT Program. Indeed, scaled testing continues in support of waste feed delivery (WFD). We recommend more fully opening the toolbox, adapting or developing tools as necessary, and sharing them within the organizations supporting the tank waste mission to meet the needs described below.

\section{Full Scale Vessel Testing}

Within the FSVT Program, the National Laboratory Technical Authority Team, consisting of Pacific Northwest National Laboratory (PNNL) and Savannah River National Laboratory (SRNL), is tasked with developing the simulants, identifying the instrumentation, and writing the test plans. The rejection of the Fluent code for design verification has discouraged the use of CFD within the project. However, our initial work on FSVT demonstrates weekly the value of having computational tools and understanding derived from models and from data and observations at smaller scale to guide testing. Specific examples include the following:

1. Identification of challenging conditions. For FSVT, we must test the most challenging condition the plant will normally encounter. The vessels receive a variety of process streams and operate over a range of operating conditions. Identifying the most difficult to mix is not always straightforward given the number of competing effects. For example, low viscosity may increase the height of the central upwell in the vessel (good), but it also causes particles to settle more rapidly (bad). Without a strong technical basis for selecting a most challenging condition, tests at both ends of the range (or even throughout) may have to be performed, at increased cost and schedule.

2. Defensible placement of instruments. While some measurements are needed in "typical" locations, many others are needed in "more challenged" positions, e.g., to confirm complete particle bottom motion or blending throughout the vessel. While placement can be based on engineering judgment and understanding based on prior scaled testing, it is difficult to quantify statistically the uncertainty in those measurements without knowing if those positions are correct. That uncertainty will likely introduce further conservatism.

3. Testing of assumptions. Some aspects of the test plan are based on assumptions about the behavior of heavy particles. The use of a simulant component that bounds the accumulation behavior of solidswithout being unrealistically challenging - is being considered. Having tools to validate these assumptions and guide component selection would be very helpful in defending the results of testing. Without them, there could be retrospective uncertainty around that chosen technical approach.

4. Extension/generalization. There are 38 PJM-mixed vessels, but only a few representative vessels will be tested. Some means to extend or generalize results from one vessel (e.g., RLD-08 for Group 5) to the other vessels (e.g., RLD-07, which is slightly taller) may be needed for design verification.

Finally, testing is time-consuming and expensive, particularly for vessels planned later in the FSVT Program that are hundreds of thousands of gallons in volume (simulant cost is estimated at around $\$ 30 / \mathrm{gal}$ per test, with multiple tests per vessel). Using a tool to predict how the system will perform in advance of testing is fiscally prudent. Likewise, should the overall cost and schedule associated with FSVT be unacceptable, the need for CFD and scaled testing to support design verification may return. 


\section{Waste Feed Delivery}

The sludges in Hanford's double-shell tanks will be mobilized and mixed using submerged jet pumps, an approach that has been proven successful for addressing hydrogen gas retention in tank 101-SY, remediation of high heat tank C-106, and mixing in AZ-101. Achieving uniform mixing has never been a requirement using this pump configuration; however, there is a need for representative sampling in the tanks used for WFD, which is much more challenging without homogeneity. Moreover, there is a need to understand whether mobilized waste will meet the WTP waste acceptance criteria and whether, for example, very large and heavy solids will be left behind in the feed tank. Mixing performance and sampling strategies are under development for the WFD tanks but have yet to be demonstrated.

To better understand mixing in WFD tanks, the tank farms contractor, Washington River Protection Solutions (WRPS), initiated a small scale testing program with a goal of predicting full scale performance (Lee 2012). Scale-up of these tests is being done with statistical correlations, but CFD is currently being explored as an aid to this process in a trial study. A full scale test is planned in a WFD tank, which will serve as a check on model predictions and allow testing of the sampling strategy.

\section{The Future}

Both aspects of the tank waste mission — tank farms and WTP — would benefit in the future from an appropriately validated tool for troubleshooting and optimization. It is unlikely that WTP will operate for 40 years without a hitch or without proposals to modify operating conditions or feeds to improve throughput or deal with problem wastes. While "limits of performance" testing for W"TP is no longer planned, having the means to evaluate problems or proposed changes to the flowsheet or basis of operations would be valuable in terms of lifecycle cost. Hence, tools developed today to support testing, planning, design, and commissioning would continue to yield returns during operation.

Predicting and controlling the properties and behavior of complex particle slurries (PNNL, 2012) would also benefit the long-term mission. Research needs remain in multi-phase flow and rheology to determine local rheological parameters from physical and chemical properties of the waste, understand colloidal and non-colloidal behavior to design rheological modifiers, and describe multi-phase turbulent flows in non-Newtonian fluids. These needs would best be addressed through integration with DOE's Office of Science.

\section{Recommendations}

Fundamentally, we need to accept that CFD has a critical role to play, and when the appropriate tools are selected, has the potential to greatly extend the impact of the testing campaign. Having done so, we specifically need the following:

1. A shared suite of CFD tools, appropriately validated for their specific use, for both Newtonian and nonNewtonian multiphase slurry flow. A workshop at PNNL in February 2013 suggested that Fluent is in many ways the most mature such code for Newtonian fluids. Los Alamos National Laboratory's Cartablanca code might be adapted for non-Newtonian rheology. PNNL's ParaFlow code (described in the appendix) has already been substantially developed and partially validated for use in tank waste processing scenarios.

2. A number of less-than-full-scale test platforms, such as those at Mid-Columbia Engineering (WTP), Monarch Machine (WRPS), PNNL, and SRNL. Acrylic vessels that provide a means for visualizing flow, mobilization, and settling behavior are particularly expedient and valuable. Scaled test platforms not only

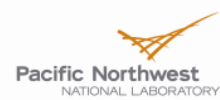


provide insight but also data for validation and verification of computational tools and for empirical scaling relations as needed and appropriate.

\section{References}

Beeman GH. 2010. Waste Treatment Plant Support Program: Summaries of Reports Produced During Fiscal Years 1999-2010. PNNL-19648, Pacific Northwest National Laboratory, Richland, WA.

DOE - U.S. Department of Energy. 2012. Letter from S. Chu to P.S. Winokur, dated October 30, 2012.

Washington, D.C.

Kurath DE et. al. 2009. Pretreatment Engineering Platform Phase 1 Final Test Report. WTP-RPT-197, Rev. 0, PNNL18894, Pacific Northwest National Laboratory, Richland, WA.

Lee KP. 2012. Waste Feed Delivery Mixing and Sampling Program Simulant Definition for Tank Farm Performance Testing. RPP-PLAN-51625, Washington River Protection Solutions, Richland WA

PNNL - Pacific Northwest National Laboratory. 2012. Scientific Opportunities to Resolve Major Legacy Waste Challenges: 1)

Waste Forms: Reducing Glass Volume and Alternatives to LAW Glass; 2) Tank Waste Chemistry: Controlling the Phases of Problematic Waste Components; 3) Multi-Phase Flow and Rheology: Enabling Safe and Effective Mixing and Transfer; and 4) Predictive Modeling and Subsurface Remediation: Enabling Site Closure, Pacific Northwest National Laboratory, Richland, WA.

Stewart CW. 2006. Hanford's Battle with Nuclear Waste Tank SY-101: Bubbles, Toils, and Troubles. Battelle Press, Columbus, $\mathrm{OH}$. 


\section{Appendix A - Case Study: Modeling Sediment Bed Erosion in Waste Feed Delivery Tank}

Development of the ParaFlow code began at Pacific Northwest National Laboratory (PNNL) in 2007 with Laboratory Directed Research and Development support. The goal was to develop a new computational fluid dynamics (CFD) tool that would be more broadly applicable to Hanford waste slurries and planned chemical processing. While other national laboratories have led extensive efforts in solids-in-gas multiphase flows, such as the National Energy Technology Laboratory for fluidized beds and risers critical to fossil energy use and refinement, the objective in this effort was to develop a general simulation capability to predict the performance of chemically complex, solids-in-liquid multiphase chemical processes for a wide range of fluid rheologies. The code also was designed for fast solution turnaround times by taking full advantage of current large-scale parallel computer systems. This capability was further developed and demonstration calculations were performed for double-shell tank mobilization and transport, slurry pipeline transport, pulse-jet mixing and ultrafiltration as part of the Advanced Multi-Phase Mixing Task under DOE Office of Environmental Management's Technology Development \& Deployment Program (Rector et al. 2009, 2010a, b, c).

A series of simulations were performed for sediment resuspension in large waste storage tanks. A rotating jet boundary condition was developed based on rotating grids centered on the rotating jets and a stationary grid for the rest of the tank. Information is passed through an interface between the grids at each time step during the transient. The surface of the sediment layer, on the bottom of the tank, changes constantly as a function of time because of solids settling and jet erosion. The location of lattice sites near the surface is represented by a normal distance and normal vector direction. The flow boundary conditions are calculated based on this location information. The rate of sediment growth due to sedimentation is a function of hindered settling velocity. The thickness and shape of the sediment bed is dynamic until a steady state is reached for the slurry makeup and specified flow conditions. The sediment height is determined by the equilibrium between the rate of deposition by hindered settling and the rate of erosion, which is a function of the turbulent shear stress at the surface of the sediment. Note that this type of calculation is not possible with traditional CFD codes, like Fluent, because they model the entire tank volume as a single multiphase flow field; particle settling can lead to a settled bed, which needs to be treated as a solid region to correctly model bed erosion, for example, by fluid jets. In ParaFlow, the sediment bed is treated as a second field where lithostatic stresses and failure mechanisms (erosion) can be computed. The rate of change in sediment thickness is used to calculate new-time values for the lattice surface distance and surface normal vectors.

The solids in some of the high-level waste tanks at Hanford include a large fraction of sub-micron particles, including aluminum hydroxides such as boehmite and gibbsite, which can form particle gels and cause nonNewtonian fluid behavior. In some cases, the fluid will exhibit shear-thinning behavior, where the viscosity decreases as a function of fluid shear rate. In other cases, the fluid will behave like a Bingham plastic. At low shear stresses, this type of suspension sets up like a solid. When the shear stress exceeds a specified yield stress, the suspension begins to flow like a fluid. The ParaFlow program has been designed to model fluids with shearthinning and Bingham plastic rheologies.

In a related study, jet mixing simulations of a scaled tank experiment were run on two of DOE's leadership class computers, Intrepid at Argonne National Laboratory and Jaguar at Oak Ridge National Laboratory. Runs on as

Page A.1

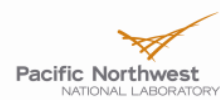


many as 32,000 processor cores were completed on Jaguar and on twice that many on Intrepid. Parallel speedup (increase in solution speed with increased number of processors) was nearly linear on Intrepid. The practical implication of this parallel performance is that transient simulations that require a long run time on a smaller computer may be completed in a small fraction of the time on a large-scale parallel machine. As a result, much more accurate physical models can be applied to reduce model uncertainty and to test the benefits and impacts of many more operational conditions. For example, a simulation that requires 2 weeks on 64 processor cores (typical of what may be used for the commercial CFD code, like Fluent) may take only 5 hours using 5000 processor cores on Olympus, the PNNL institutional computer that has 20,000 processor cores available.

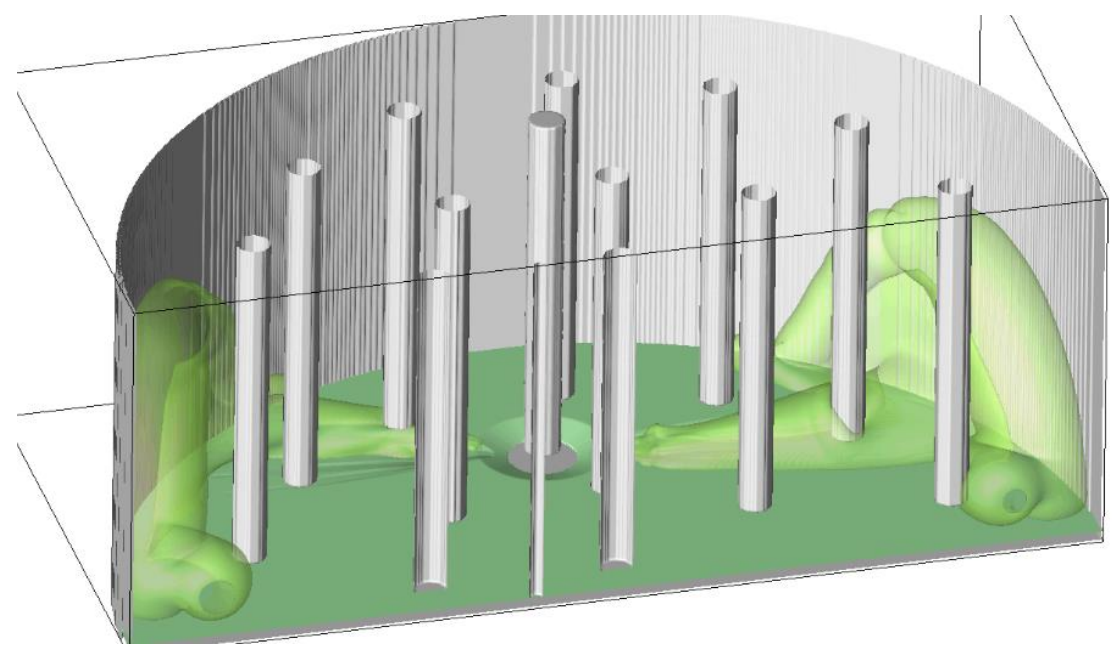

ParaFlow Simulation Showing Calculated Concentration and Sediment Isosurfaces During Waste Feed Delivery Tank Sediment Re-suspension

\section{References}

Rector DR, ML Stewart, and AP Poloski. 2009. "Modeling of Sediment Bed Behavior for Critical Velocity in Horizontal Piping." 2009 Waste Management Symposium, Phoenix, Arizona, WM Symposia, Inc. Available online at http://www.wmsym.org/abstracts/2009/index.html.

Rector DR and ML Stewart. 2010a. "A semi-implicit lattice method for simulating flow." J. Comput. Phys. 229: 6732-6743.

Rector DR and ML Stewart. 2010b. "Modeling of Leaching Filter Pressure Drop and Fouling Behavior.” 2010 Waste Management Symposium, Phoenix, Arizona, WM Symposia, Inc. Available online at http://www.wmsym.org/abstracts/2010/index.html.

Rector DR, ML Stewart, TE Michener and J Shultz. 2010c. “Advanced Multiphase Mixing." Presented at DOE Environmental Management's Technical Exchange 2010. Atlanta, GA. 